\title{
Bone mineral density and vertebral compression fracture rates in ankylosing spondylitis
}

\author{
S Donnelly, D V Doyle, A Denton, I Rolfe, E V McCloskey, T D Spector
}

\begin{abstract}
Objective-To examine the relationship between disease severity and bone density as well as vertebral fracture risk in patients with ankylosing spondylitis (AS). Methods-Measurements were taken for bone mineral density (BMD) and vertebral fracture rates in 87 patients with AS. BMD was measured at the hip (femoral neck -FN), lumbar spine (L1-L4LS) and for the whole body using a hologic-QDR-1000/W absorptiometer. An algorithm based on normal female ranges of vertebral heights was used to define a fracture as occurring when two vertebral ratios were each three standard deviations below the calculated mean of the controls. Results-Patients with AS had significantly lower FN-BMD in proportion to disease severity (based on a Schober index) and disease duration. LS-BMD was also reduced in early disease, but in patients with advanced $A S$ it had increased considerably. Nine vertebral fractures $(10.3 \%)$ were identified which was considerably higher than expected when compared with a fracture of $1.9 \%$ in a control population of 1035 females of a similar age range. Patients with AS with fractures were significantly older, more likely to be male, had longer disease duration and more advanced spinal limitation with less mobility. There was no significant reduction in lumbar spine or femoral neck bone density in the fracture group.
\end{abstract}

Conclusions-Vertebral fractures that result from osteoporosis are a feature of longstanding AS. BMD used as a measure of osteoporosis of the spine in advanced AS is unreliable probably as a result of syndesmophyte formation and does not predict the risk of vertebral fracture. Alternative sites such as the neck of the femur should be used for sequential assessment of BMD in AS.

(Ann Rheum Dis 1994; 53: 117-121)

A recent report $^{1}$ demonstrated marked osteoporosis in the lumbar spine and femoral neck of 25 patients with early AS [mean disease duration-11.5 years, mean (SD) Schober score $6.58(1.01)$ ] who had minimal clinical and radiological evidence of disease, good spinal mobility and normal or increased levels of exercise over controls. There was a significant reduction in BMD of the lumbar spine and femoral neck in these patients, but this was not found at the wrist (carpal bones). In a study of 28 patients with a more advanced disease $^{2}$ (mean duration-20.3 years, Schober's-all $<5 \mathrm{~cm}$ ), the same authors report a continued loss of bone occurring in the femoral neck but with normal lumbar spine BMD.

To examine in detail the relationship between disease severity, bone loss and vertebral fractures we evaluated a larger group of 87 AS patients randomly. To overcome some of the difficulties of vertebral fracture definition we used a semi-automated morphometric method of diagnosis and compared the results with a large population based comparison group.

\section{Patients and methods}

PATIENTS

We studied 87 consecutive patients with AS attending a single East London hospital clinic over a six month period. None had been referred from another hospital and none refused study entry. Sixty two were male $(71 \cdot 3 \%)$ and 25 female $(28 \cdot 7 \%)$. Eighty three patients were white $(95.4 \%)$ and four were of Asian background $(4 \cdot 6 \%)$. Seventy two patients $(82.5 \%)$ had AS without an associated condition; seven had psoriatic arthritis $(8 \%)$, seven inflammatory bowel disease (five ulcerative colitis and two Crohn's disease) and a single patient had Reiter's syndrome. Forty patients $(46 \%)$ had spinal involvement only; in $16(18.5 \%)$ there was associated hip arthritis, one had shoulder involvement and 12 (14\%) had additional peripheral joint arthritis; in the remaining $18(20.5 \%)$ there was some combination of associated joint involvement. All patients were assessed clinically using a modified Schober's test, ${ }^{3}$ Tragus-wall distance (distance between the tragus and wall with the patient asked to stand heels and back against a wall), and measurement of chest expansion. All patients had lateral radiographs of the lumbar and thoracic spines (2 films) taken at a standard target-to-film distance of $101 \mathrm{~cm}$. Thoracic films were centred on $\mathrm{T} 9$ and lumbar films on L3. Radiographs were read via an automated program by a single 'blind' observer after positioning on a rear illuminated digitising table (Kontron). Using a transparent crosswire cursor the anterior, central and posterior heights of each vertebra from $\mathrm{T} 4$ to L5 were measured and the results transferred to computer database. 
The criteria used for definition of a vertebral fracture are based on an algorithm of normal female vertebral heights as described in detail elsewhere by McCloskey et al. ${ }^{4}$ At present, no male database exists for comparison purpose. Normal ratios of vertebral height were defined from the spine radiographs of 100 asymptomatic women (age $45-50$ years, mean $47 \cdot 5$ ) from within the control population who were randomly selected and free of back pain or known osteoporotic fracture. In these controls posterior vertebral height was found to vary with spinal level and a 'mean predicted posterior height' (PP) was calculated from posterior heights of up to four adjacent vertebrae. Subsequently, each anterior (A), central $(C)$ and posterior $(P)$ vertebral height was expressed as a ratio of PP. The normal ranges of these ratios were similar to those derived in different female populations. ${ }^{5-7}$ From this reference range, mean ratios and their standard deviations (SD) were calculated for each vertebra from T4 to L4. This reference population then provided an algorithm used for the definition of vertebral fracture. For the study population, the same four measurements were recorded on database and fractures were then classified as being anterior, central, posterior and crush in type. Fractures were diagnosed in any particular vertebra if the relevant two sets of ratios were both below the 3 rd centile limit for that same vertebra derived from the measurements of the 100 control women. Using this algorithm, which by definition identifies deformities below the $0 \cdot 1$ centile limit (that is, $3 \mathrm{SDs}$ ), the mean percentage decrease in vertebral height for an anterior wedge deformity $((\mathrm{P}-\mathrm{A}) / \mathrm{P} \times 100)$ approximates to $18 \%(14-21 \%)$. This is similar to the cut-off reported using a separate defined algorithm. ${ }^{8}$ The false positive rate using this method is estimated at approximately $1 \%{ }^{4}$ and the method is highly sensitive.

BMD of the lumbar spine, femoral neck and whole body was measured using a HologicQDR-1000/W dual energy $x$ ray absorptiometer which has a precision in our hands of $0.7 \%$ for LS and $1.5 \%$ for FN. A 'Z score' was calculated for each lumbar spine (LS), femoral neck (FN) and whole body (WB) scan result. ' $\mathrm{Z}$ score' is the number of standard deviations of any individual result from the age and sex related population mean (normal ranges being provided by manufacturers of the bone densitometer).

\section{COMPARISON GROUP}

Lateral spine $x$ rays were obtained from a comparison population (The Chingford Study) derived from the age/sex register of a six partner east London general practice of approximately 11000 patients described in detail elsewhere. ${ }^{9}$ This included 1035 women aged between 45 and 69 years (mean 55.4 years) which represented an overall response rate of $77 \%$. All women lived within a six mile radius of the hospital and $98 \%$ were white.

\section{STATISTICS}

Patients with AS were grouped by clinical severity based upon a Schober's index corresponding to $0-1.9 \mathrm{~cm}$ (severe AS), 2-3.9 $\mathrm{cm}$ (moderate AS) and $\geqslant 4 \mathrm{~cm}$ (mild AS). The means of these groups were compared using Student's $t$ test after testing that the data approximated to a normal distribution and proportions were compared with the $\mathrm{Chi}$ square statistic and using analysis of covariance (SAS software).

\section{Results}

A comparison of male and female AS patients (table 1) showed that lumbar spine density was significantly lower in males (mean male LS$\mathrm{BMD}=0.99(0.69-1.39)$, mean female LS $\mathrm{BMD}=1.07(0.68-1 \cdot 39))$. Both sexes were well matched in terms of age, disease duration and severity of disease. As expected, patients with more severe disease (Schober $<2$ ) were older $(p<0.001$ versus mild AS-Shober $>4)$, had greater disease duration $(p<0.001)$ and progressive deterioration in clinical measures of severity $(p<0.001$ for Tragus-wall distance

Table 1 Comparison and characteristics of male and female patients with AS

\begin{tabular}{|c|c|c|c|c|c|c|c|c|}
\hline & $\begin{array}{l}\text { Number } \\
(\%)\end{array}$ & $\begin{array}{l}\text { Mean }(S D) \\
\text { age Years }\end{array}$ & $\begin{array}{l}\text { Mean }(S D) \\
\text { disease duration } \\
\text { Years }\end{array}$ & $\begin{array}{l}\text { Mean }(S D) \\
\text { tragus wall }\end{array}$ & $\begin{array}{l}\text { Mean (SD) } \\
\text { Schober's }\end{array}$ & $\begin{array}{l}\text { Mean }(S D) \\
\text { spine } Z\end{array}$ & $\begin{array}{l}\text { Mean }(S D) \\
\text { femur Z }\end{array}$ & $\begin{array}{l}\text { Mean (SD) } \\
\text { whole body } Z\end{array}$ \\
\hline $\begin{array}{l}\text { Male } \\
\text { Female } \\
\text { P value }\end{array}$ & $\begin{array}{l}62(71 \cdot 3) \\
25(28 \cdot 7)\end{array}$ & $\begin{array}{l}43.5(12.3) \\
44 \cdot 8(11.9) \\
P=0.64\end{array}$ & $\begin{array}{l}16 \cdot 3(9 \cdot 8) \\
16 \cdot 6(12 \cdot 3) \\
P=0 \cdot 894\end{array}$ & $\begin{array}{l}14 \cdot 6(5 \cdot 9) \\
12 \cdot 7(4 \cdot 9) \\
P=0 \cdot 164\end{array}$ & $\begin{array}{l}3.04(1.67) \\
2.76(1.75) \\
P=0.487\end{array}$ & $\begin{array}{l}-0.58(1.39) \\
+0.78(1.63) \\
P<0.001\end{array}$ & $\begin{array}{l}-0.94(1.11) \\
-0.43(1.16) \\
P=0.063\end{array}$ & $\begin{array}{l}+0.08(0.82) \\
+0.60(0.98) \\
P=0.013\end{array}$ \\
\hline
\end{tabular}

Table 2 Bone mineral density in males and females with different grades of severity of $A S$

\begin{tabular}{|c|c|c|c|c|c|c|c|c|c|c|c|c|c|}
\hline & $\begin{array}{l}\text { Number } \\
(M / F)\end{array}$ & $\begin{array}{l}\text { Mean } \\
\text { L spine } \\
Z \text { score }\end{array}$ & $\begin{array}{l}(S D) \\
(S E M)\end{array}$ & $\begin{array}{l}\text { Mean } \\
\text { male } \\
\text { L spine } \\
Z \text { score }\end{array}$ & $\begin{array}{l}(S D) \\
(S E M)\end{array}$ & $\begin{array}{l}\text { Mean } \\
\text { female } \\
\text { L spine } \\
Z \text { score }\end{array}$ & $\begin{array}{l}(S D) \\
(S E M)\end{array}$ & $\begin{array}{l}\text { Mean } \\
\text { femur } \\
Z \text { score }\end{array}$ & $\begin{array}{l}(S D) \\
(S E M)\end{array}$ & $\begin{array}{l}\text { Mean } \\
\text { male } \\
\text { femur } \\
Z \text { score }\end{array}$ & $\begin{array}{l}(S D) \\
(S E M)\end{array}$ & $\begin{array}{l}\text { Mean } \\
\text { female } \\
\text { femur } \\
Z \text { score }\end{array}$ & $\begin{array}{l}(S D) \\
(S E M)\end{array}$ \\
\hline $\begin{array}{l}\text { Schober 0-1.9 } \\
\text { (severe) }\end{array}$ & $26(17 / 9)$ & $+0 \cdot 50$ & $\begin{array}{l}(2 \cdot 16) \\
(0 \cdot 42)\end{array}$ & -0.08 & $\begin{array}{l}(2 \cdot 11) \\
(0 \cdot 51)\end{array}$ & $+1 \cdot 61$ & $\begin{array}{l}(1 \cdot 88) \\
(0.63)\end{array}$ & $-1 \cdot 04$ & $\begin{array}{l}(1 \cdot 12) \\
(0 \cdot 23)\end{array}$ & $-1 \cdot 29$ & $\begin{array}{l}(1 \cdot 13) \\
(0 \cdot 29)\end{array}$ & -0.57 & $\begin{array}{l}(0.83) \\
(0 \cdot 29)\end{array}$ \\
\hline $\begin{array}{l}\text { Schober 2-3.9 } \\
\text { (moderate) }\end{array}$ & $23(17 / 6)$ & $-0 \cdot 54$ & $\begin{array}{l}(0 \cdot 92) \\
(0 \cdot 19)\end{array}$ & -0.65 & $\begin{array}{l}(0 \cdot 83) \\
(0 \cdot 20)\end{array}$ & $-0 \cdot 20$ & $\begin{array}{l}(1 \cdot 13) \\
(0 \cdot 46)\end{array}$ & $-0 \cdot 88$ & $\begin{array}{l}(1 \cdot 00) \\
(0 \cdot 21)\end{array}$ & -0.94 & $\begin{array}{l}(0 \cdot 85) \\
(0 \cdot 21)\end{array}$ & $-0 \cdot 72$ & $\begin{array}{l}(1.44) \\
(0.59)\end{array}$ \\
\hline $\begin{array}{l}\text { Schober } 4 \text { or }> \\
\text { (mild) }\end{array}$ & $38(28 / 10)$ & -0.46 & $\begin{array}{l}(1 \cdot 29) \\
(0 \cdot 21)\end{array}$ & -0.88 & $\begin{array}{l}(1 \cdot 01) \\
(0 \cdot 19)\end{array}$ & +0.62 & $\begin{array}{l}(1 \cdot 40) \\
(0 \cdot 43)\end{array}$ & -0.59 & $\begin{array}{l}(1 \cdot 22) \\
(0 \cdot 20)\end{array}$ & -0.75 & $\begin{array}{l}(1 \cdot 19) \\
(0 \cdot 22)\end{array}$ & $-0 \cdot 15$ & $\begin{array}{l}(1 \cdot 26) \\
(0 \cdot 40)\end{array}$ \\
\hline
\end{tabular}

(SD) = standard deviation

$(\mathrm{SEM})=$ standard error of mean 

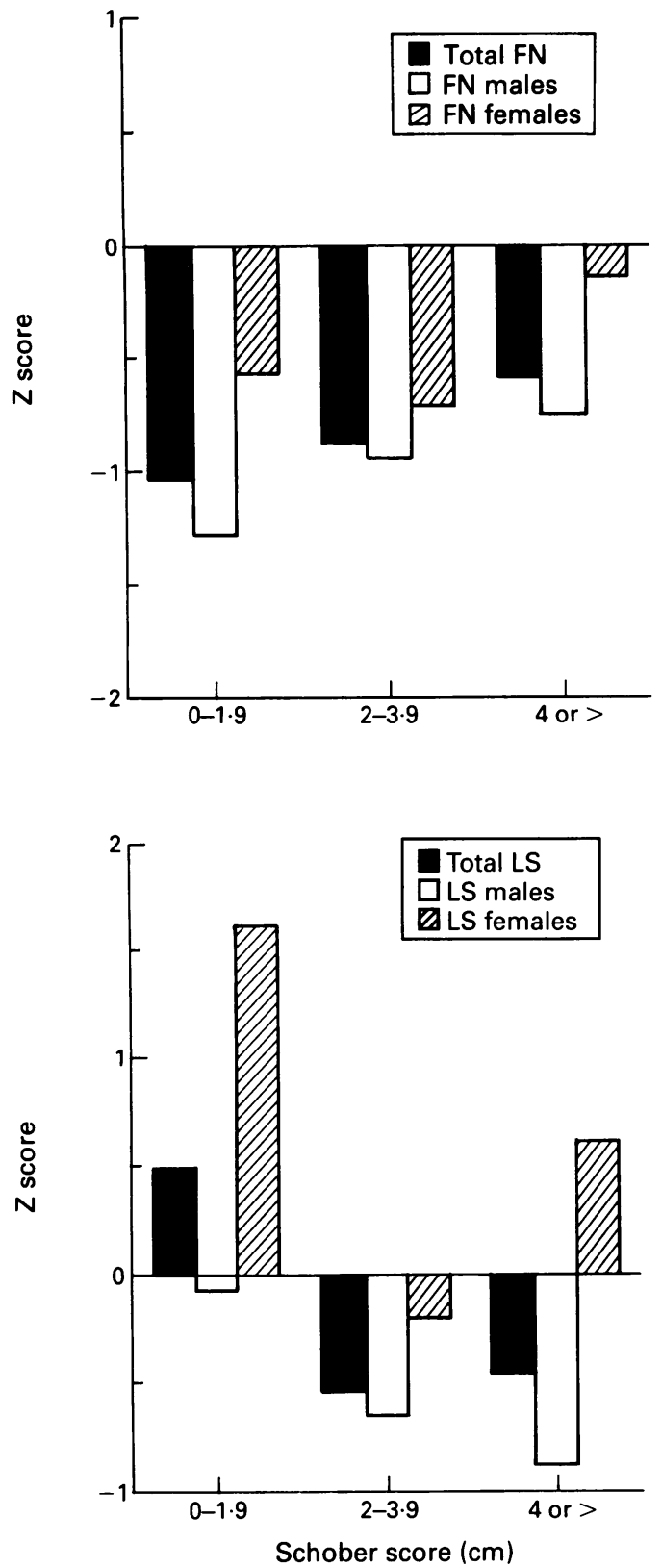

Change in $F N-B M D$ and $L S-B M D$ in mild, moderate and severe $A S$.

and chest expansion). Table 2 shows change in bone density by Schober group and sex. In males with mild AS, bone density is reduced in the spine and femoral neck. In the corresponding females BMD was low at the FN but increased in the spine. In moderate disease there is a further reduction in overall LS and FN-BMD but in severe disease although overall FN-BMD was further reduced LS-BMD had increased considerably (figure). In our patients, females with severe disease had a particularly high LS-BMD, although overall female numbers in each subgroup was small. WB-BMD score does not reflect axial demineralisation but shows a similar pattern of BMD reduction in male patients with AS compared with females.

No difference in BMD was seen in patients with AS with and without associated inflammatory bowel disease or psoriatic arthritis. However, patients with AS with associated hip involvement $(n=16)$ had significantly higher
LS-BMD than those with spinal involvement only $(\mathrm{n}=40)-(Z=+0.38 v-0.63 \mathrm{p}=0.017)$ but these two groups had similar FN-BMD $(\mathrm{Z}=-0.71 v-0.87 \mathrm{p}=0.65)$. Patients with AS with peripheral joint involvement $(n=12)$ did not differ in BMD from those who had spinal involvement alone. In those with associated hip involvement, there was a female predominance $(13 / 25-52 \%$ v $21 / 62-33 \cdot 8 \%$ ), no significant age difference $(46.6 v 42.8$ years $\mathrm{p}=0.197)$, more severe spinal disease (Schober score 1.68 $v 2.4 \mathrm{cms} p<0.001)$ and longer disease duration $(20.3 v 14.2$ years $p=0.016)$ than those with spinal involvement alone. Those with peripheral joint involvement did not differ in age, disease duration or severity of spinal disease from those with spinal AS alone.

Seventy five $x$ rays were available for analysis of fractures. There were nine fractures $(10.3 \%)$ which had occurred in eight patients, the commonest fracture site being T8-T10 (five fractures). Only two fractures occurred outside the thoracic spine (L2 and L4 vertebrae). The fracture rate for male patients was $13.7 \%$ $(7 / 51)$ and for females $8 \cdot 3 \%(2 / 24)$. Five fractures involved central collapse only (biconcave-in one patient occurring at both T12 and L4) and three patients had crush fractures. A single anterior wedge fracture occurred at T6 vertebra. In those with fractures, none had symptoms clearly attributable to this or previous $x$ ray screeening requested to outrule a fracture. A comparison of those with fractures to those without showed them to be older (mean age 55.4 $v 42.5$ years $\mathrm{p}=0.002$ ), to have a longer disease duration $(25.2 v 15.4$ years $\mathrm{p}=0.007)$, a lower mean Schober score $(1.83 v 3.09 \mathrm{cms} \mathrm{p}=0.034)$ and a greater mean Tragus-wall distance $(18.7 v$ $13.5 \mathrm{cms} p=0.009$ ). There was no significant reduction in BMD in the fracture group (spine $\mathrm{Z}-0.31 v-0.18$ for non fracture group $\mathrm{p}=0.81$, femur $\mathrm{Z}-0.81 v-0.80 \mathrm{p}=0.97) . X$ rays were analysed on 1035 women from the comparison population. Using the same definition, 20 women had fractures, a prevalence of $1.9 \%(95 \%$ CI $1 \cdot 5-4 \cdot 0)$, the most frequent fracture sites being $\mathrm{T} 10$ and $\mathrm{Ll}$ vertebrae. Of those aged between 45 and 49 years $(n=178)$ from the comparison group, the fracture rate was only $1 \cdot 1 \%(95 \%$ CI $0 \cdot 4-2 \cdot 7)$.

Six patients (two men, four women) had ever taken oral corticosteroids (dose between 2.5 and $5 \mathrm{mg}$, mean duration 4.4 years) and their $\mathrm{BMD}$ was non-significantly reduced (spine $\mathrm{Z}$ $-0.48 v-0.17 \mathrm{p}=0.64$, femur $Z-1.01 v-0.78$ $\mathrm{p}=0.63$ ) compared to the non-steroid group. No fractures were seen in the six patients treated with steroids.

\section{Discussion}

In this cross-sectional study we have confirmed that reduced mineralisation of the lumbar spine and femoral neck is a feature of early AS and is more pronounced in male patients. In trabecular bone, BMD progressively falls in parallel with increasing severity of spinal disease. In advanced AS, LS-BMD was 
increased. In our patients, LS-BMD was consistently higher in females although overall numbers were small. It seems likely that syndesmophyte formation which is a feature of advanced spinal disease results is an increase in recorded BMD score in such patients and masks the actual underlying progressive demineralisation of vertebral bodies as demonstrated by Devogelaer $e t a l^{10}$ in a small patient group. A similar false increase in lumbar spine bone density has recently been reported in elderly females with osteoporosis and osteophytes. ${ }^{11}$ The true pattern of demineralisation of the axial skeleton in AS may be more accurately reflected by FN-BMD which progressively falls with disease duration and increasing spinal restriction. Whole body measurements of bone density do not appear to provide useful information in this context and are expensive and time consuming.

We used a modified Schober score to define clinical status in our patients and this correlated with other clinical indices of disease severity and showed an expected negative correlation with disease duration (data not shown). Vertebral fractures in AS occurred with increasing age, disease duration and severity of disease. In this study, however, $\mathrm{BMD}$ as a single measure taken at any site was not a good predictor of likelihood of fracture. Without a gold standard, the definition of vertebral fracture remains controversial although most authorities believe that morphometric methods which assess relative ratios are the most reliable. ${ }^{4}$ The method used, including the use of two separate criteria to define the presence of a deformity with a cutoff of 3SD, has been found to be similar in terms of prevalence of fracture to the $4 \mathrm{SD}$ method used in other centres. ${ }^{5}$ Greater specificity would result from a 4SD cut-off or $25 \%$ decrease in height required for a deformity but at the cost of decreased sensitivity. ${ }^{4}$

In the present study patients' vertebral ratios were compared against those of a female reference population. This resulted in a fracture rate of $8.3 \%$ in females and $13.7 \%$ in males. Ideally, one would compare male fractures against aged matched male controls. Such a control male database does not exist at present, although limited previous data suggests that vertebral fractures are less common in men then in women. ${ }^{12}$ The definition of vertebral fracture in this study depends upon a comparison of vertebral ratios rather than measured height and therefore is unlikely to be strongly biased by a sex effect. In spite of this, it is possible that for various reasons (such as trauma) male and female vertebral ratios may differ slightly and this could affect our results. Reported vertebral deformities, especially wedge deformity, may result from alternative mechanisms such as spondylodiscitis (resulting in erosions at the anterior margins of the vertebral body, giving the spurious appearance of wedging) and it is possible this could influence our results (although we only report a single wedge fracture). Nevertheless, we observed a greater than four fold increase in female fracture rates compared with controls and it is likely that the observed male fracture rate is similarly increased. This confirms previous reports of increased vertebral fractures in $\mathrm{AS}^{10}{ }^{13}{ }^{14}$ which are likely to result from demineralisation as well as alterations in the pattern of mechanical stresses within the spine resulting from changes in vertebral shape. Caution in the interpretation of cross-sectional studies has previously been emphasised ${ }^{15}$ and it is possible that our fracture rate could be altered by patients with early AS as yet not diagnosed or referred to the hospital, or by patients with advanced AS who attended the hospital but died before study entry.

The cause of osteoporosis occurring in AS remains unknown. Demineralisation of the axial skeleton is an early feature of AS, ${ }^{1}$ initially sparing cortical bone and this would support a concept of enhanced bone resorption or reduced bone deposition occurring locally at inflammatory sites possibly mediated via cytokines. ${ }^{16}$ However, the demonstration of reduced $\mathrm{BMD}$ in cortical bone (the wrist) in advanced disease ${ }^{2}$ and in the femoral neck in early disease suggests a systemic mediator may be involved. Furthermore, the reduction in axial bone density in early disease occurred in patients who had normal spinal mobility and normal or increased levels of exercise over controls suggesting that this does not result from spinal stiffness or immobility. The study by Will et $a l^{1}$ provided biochemical evidence suggesting that osteoporosis in AS is the result of reduced rather than increased bone turnover. This is further supported in a recent trial by Franck and $\mathrm{Keck}^{17}$ who demonstrated that bone turnover in patients with AS is characterised by low bone formation (measured by low serum osteocalcin) in the presence of normal levels of calcium regulating hormones (parathyroid hormone and 1,25-dihyroxyvitamin $\quad$ D). The greater reduction in axial BMD in males is marked and presently is difficult to explain. It may involve a hormonal effect or a different pattern of disease between sexes. A longitudinal study of bone density in AS would allow more accurate assessment of the rate and pattern of demineralisation and is in progress at this centre.

These cross-sectional results suggest that with progressive AS there is continued demineralisation of the axial skeleton which is accurately measured by FN-BMD, contributing to a significantly increased rate of vertebral fracture. Vertebral compression fractures occur at more than five times the expected rate and are frequently unrecognised as a complication of AS. Bone density of the spine in AS as measured by dual energy $x$ ray absorptiometer is unlikely to accurately reflect the state of mineralisation in the spine and more emphasis should be placed on measures on FN-BMD.

1 Will $R$ Palmer $R$, Bhalla A $K$, Ring $R$, Calin A Osteoporosis in early ankylosing spondylitis: a primary Osteoporosis in early ankylosing spondylitis:
pathological event? Lancet 1989; ii: 1483-85. 
2 Will R, Palmer R, Bhalla A K, Ring F, Calin A. Bone loss as well as bone formation is a feature of progressive ankylosing spondylitis. Br F Rheumatol 1990; 29: 498-9.

3 Gran J T. An epidemiological survey of the signs and symptoms of ankylosing spondylitis. Clin Rheum 1985; 4: 161-9.

4 McCloskey E V, Spector T D, Eyers K S, Fern D E O'Rourke N, Vasikaran S, Kanis J A. The assessment of vertebral deformity: a method for use in population studies and clinical trials. Osteoporosis Int 1993; 3 $138-47$.

5 Spector T D, McCloskey E V, Doyle D V, Kanis J A Prevalence of vertebral fracture in women and the Prevalence of vertebral fracture in women and the
relationship with bone density and symptoms: The Chingford Study. $\mathcal{f}$ Bone Min Research 1993; 8(7): Chingford

6 Black D M, Cummings S R, Stone K, Hudes E, Palmero L, Steiger P. A new approach to defining normal vertebral dimensions. $\mathcal{F}$ Bone Min Research 1991; 6: 207-16.

7 Melton L J, Kan S H, Frye M A, Wahner H W, O'Fallon W M, Riggs B L. Epidemiology of vertebral fractures in women. Am f Epidemiol 1989; 129: 1000-11.

8 Eastell R, Cedel S L, Wahner H W, Riggs B L, Melton III $\mathrm{L} J$. Classification of vertebral fractures. $\mathfrak{f}$ Bone Min L J. Classification of vertebral fractures. $\mathcal{F}$ Bone Min

Hart D J, Spector T D. The relationship of obesity, fat distribution and osteoarthritis in women in the general population: The Chingford Study. $\mathcal{F}$ Rheumatol 1993; 20: 331-5.

10 Devogelaer J P, Baudouin M, Malghem J, De Deuxchaisnes $\mathrm{CN}$. Appendicular and vertebral bone mass in ankylosing spondylitis. Arthritis Rheum 1992; 35: 1062-7.

11 Masud T, Langley S, Wiltshire P, Doyle D V, Spector T D. The effect of spinal osteophytosis on bone mineral density measurements in patients with vertebral osteoporosis. $B M \mathcal{F}$ 1993; 307: 172-3.

12 Cummings S R, Kelsey J L, Nevitt M C, O'Doyd K J. Epidemiology of osteoporosis and osteoporotic fractures. Epidemiol Rev 1985; 7: 178-207.

13 Ralston S H, Urquhart G D K, Brzeski M, Sturrock R. Prevalence of vertebral compression fractures due to osteoporosis in ankylosng spondylitis. BMF 1990; 300: 563-5.

14 Cooper C, Carbone L, Clement M, Atkinson E, O'Fallon W M, Melton III L J. Fracture risk in patients with ankylosing spondylitis: a population based study. Arthritis Rheum 1992; 35(suppl 1): S243.

15 Fries J F, Singh G, Bloch D A, Calin A. The natural history of ankylosing spondylitis: is the disease really changing? of ankylosing spondylitis: is the

16 Raisz L G. Local and systemic factors in the pathogenesis of osteoporosis. New Eng $\mathcal{F}$ Med 1988; 37: 453-8.

17 Franck H, Keck E. Serum osteocalcin and vitamin D metabolites in patients with ankylosing spondylitis. Ann Rheum Dis 1993; 52: 343-6. 